\title{
Senam Lansia terhadap Penurunan Tekanan Darah pada Lansia
}

\author{
Elderly Gymnastics with a Decrease in Systolic Blood Pressure in the Elderly \\ Farida Yuliani* \\ Sekolah Tinggi Ilmu Kesehatan Majapahit, Mojokerto \\ *Corresponding author : farida yuliani80@yahoo.co.id
}

\section{ABSTRAK}

Proses kehidupan yang ditandai dengan penurunan kemampuan tubuh untuk beradaptasi dengan stres lingkungan adalah menjadi tua, hal itu merupakan proses alamiah, yang berarti seseorang telah melalui tiga tahap kehidupannya yaitu anak, dewasa dan tua. Bertambahnya umur, fungsi fisiologis mengalami penurunan akibat proses degeneratif. Sehingga memicu terjadinya penyakit degeneratif baik yang menular ataupun tidak. Penyakit tidak menular pada lansia salah satunya adalah hipertensi. Penelitian ini bertujuan untuk mengetahui perbedaan tekanan darah lansia yang diukur setelah melakukan senam di Dusun Tambak Rejo, Desa Gayaman Kecamatan Mojoanyar

Penelitian ini merupakan penelitian analitik. Variabel independen dalam penelitian ini adalah senam lansia, sedangkan variabel dependennya adalah hasil tekanan darah. Populasi dalam penelitian ini adalah semua ibu yang memiliki hipertensi di Dusun Tambak Rejo Desa Gayaman Kecamatan Mojoanyar sebanyak 12 orang. Sampel diambil dengan Total Sampling. Penelitian ini dilakukan pada bulan Agustus 2018. Instrumen yang dipakai adalah checklist dan analisa data menggunakan Paired sample T Test.

Hasil penelitian menunjukkan dari 12 responden, sebagian besar responden berusia 40-65 tahun sebanyak 83,4\%, dengan hasil rata-rata sistol sebelum senam adalah 151,65 sedangkan sesudah senam didapatkan rata-rata 135.83. berdasarkan uji Paired Sample T Test didapatkan derajat kemaknaan 0,05 sehingga $H_{0}$ ditolak dan H1 diterima artinya ada hubungan senam lansia dengan penurunan tekanan darah sistol.

Senam lansia membawa pengaruh yang baik terhadap tekanan darah pada lansia yang hipertensi. oleh karena itu hasil penelitian ini dapat digunakan sebagai motivasi agar lansia tetap rajin melakukan senam lansia. Saran kita sebagai tenaga kesehatan perlunya menjaga kestabilan tekanan darah dengan rajin melakukan senam lansia disetiap posyandu serta menjaga pola makan dan gaya hidup yang sehat.

Kata kunci : Senam lansia, tekanan darah

\section{ABSTRACT}

The life process which is characterized by a decrease in the body's ability to adapt to environmental stress is to grow old, it is a natural process, which means that a person has gone through three stages of his life, namely child, adult and old. Increasing age, physiological function decreases due to degenerative processes. So that it triggers the occurrence of degenerative diseases, whether infectious or not. Non-communicable diseases in the elderly, one of which is hypertension. This study aims to determine differences in elderly blood pressure measured after doing gymnastics in Tambak Rejo Hamlet, Gayaman Village, Mojoanyar District

This research is an analytical research. The independent variable in this study is elderly gymnastics, while the dependent variable is the result of blood pressure. The population in this study were all mothers who had hypertension in Tambak Rejo Hamlet, Gayaman Village, Mojoanyar District, as many as 12 people. Samples were taken by Total Sampling. This research was conducted in August 2018. The instrument used was a checklist and data analysis using Paired sample T Test.

The results showed that of the 12 respondents, the majority of respondents aged 40-65 years were 83.4\%, with the average result of systole before gymnastics was 151.65 while after gymnastics obtained an average of 135.83. Based on the Paired Sample T Test test obtained a significance level of 0.05 so that $\mathrm{HO}$ is rejected and H1 is accepted meaning there is an elderly gymnastic relationship with a decrease in systolic blood pressure.

Elderly gymnastics brings a good influence on blood pressure in hypertensive elderly. therefore the results of this study can be used as motivation so that the elderly still diligently do elderly exercises. Our advice as health workers is the need to maintain blood pressure stability by diligently doing elderly gymnastics in every posyandu and maintaining a healthy diet and lifestyle.

Keywords: elderly gymnastics, blood pressure 


\section{PENDAHULUAN}

Proses kehidupan yang ditandai dengan penurunan kemampuan tubuh untuk beradaptasi dengan stres lingkungan adalah menjadi tua, hal itu merupakan proses alamiah, yang berarti seseorang telah melalui tiga tahap kehidupannya yaitu anak, dewasa dan tua (Nugroho, 2008)

Seiring dengan keberhasilan pemerintah dalam pembangunan nasional, telah mewujudkan hasil yang positif di berbagai bidang sehingga dapat meningkatkan kualitas kesehatan penduduk serta peningkatan kualitas usia harapan hidup. Akibatnya jumlah penduduk yang berusia lanjut meningkat dan bertambah dengan cepat. meningkatnya derajat kesehatan penduduk akan berpengaruh terhadap meningkatnya usia harapan hidup di Indonesia. Pada tahun 2000 diperkirakan jumlah lanjut usia meningkat menjadi 9,99\%dari seluruh penduduk Indonesia dengan umur harapan hidup 65-70 tahun akan meningkat menjadi $11,09 \%$ dengan umur harapan hidup 70-75 tahun.(Bandiyah, 2009)

Proses penuaan terjadi akibat bertambahnya umur seseorang, sehingga memicu terjadinya penyakit degeneratif baik yang menular ataupun tidak. Penyakit tidak menular pada lansia salah satunya adalah hipertensi. (Maryam, 2008).

Hipertensi merupakan faktor resiko dari penyakit kardiovaskuler. Penyakit jantung merupakan salah satu penyebab risiko yang ditimbulkan oleh hipertensi. Dikatakan hipertensi apabila tekanan darah sistolik $\geq 140$ $\mathrm{mmHg}$ dan tekanan darah diastolik $\geq 90 \mathrm{mmHg}$. Hipertensi yang tidak ditangani dengan baik sangat berbahaya bagi kesehatan beberapa organ karena tekanan darah yang tinggi dapat menyebabkan kerusakan.

Terjadi perbedaan kualitas hidup antara individu yang terkena hipertensi dengan individu yang sehat dimana terjadi perbedaan fungsi, peran fisik, emosional, nyeri tubuh, kesehatan umum, vitalitas dan kesehatan mental terjadi perubahan yang signifikan. Kualitas hidup lansia berdampak buruk jika sistem tubuh lansia mengalami hipertensi.

Peningkatan kualitas hidup secara mental yang diperoleh melalui aktivitas fisik dapat mengurangi stres, meningkatkan rasa antusias dan rasa percaya diri, serta mengurangi kecemasan dan depresi seseorang terkait dengan penyakit yang dialaminya. Senam yang dilakukan oleh lansia telah menunjukkan terjadi peningkatan kualitas hidup, sehingga menunjukkan adanya pengaruh signifikan senam bugar lansia terhadap kualitas hidup penderita hipertensi.

\section{METODE PENELITIAN}

Jenis penelitian yang digunakan dalam penelitian ini adalah penelitian analitik dengan menggunakan metode pendekatan cross sectional. Dalam penelitian ini peneliti mengukur tekanan darah pada awal setelah dilakukan senam dan setelah senam kelima. Populasi dalam penelitian adalah lansia mengalami hipertensi sebanyak 12 orang. Pengumpulan data dilakukan dengan pengukuran tekanan darah setelah dilakukan senam. Kedua variabel dilakukan dengan Paired Sample T Test.

\section{HASILDAN PEMBAHASAN}

Berdasarkan Tabel 1 bahwa sebagian besar responden berusia antara 40 - 65 tahun yaitu sebanyak 10 orang $(83,4 \%)$.

Berdasarkan Tabel 2 bahwa sebagian besar responden tidak pernah bekerja yaitu sebanyak 9 orang $(75 \%)$.

Berdasarkan Tabel 3, hasil uji normalitas dengan Kolmogorov Smirnov didapatkan bahwa variabel data diatas berdistribusi normal dengan nilai $\mathrm{P}>0,05$

Pengaruh senam lansia terhadap penurunan tekanan darah pada lansia di Dusun Tambak Rejo dari 12 responden dengan hasil rata-rata 
Tabel 1 Distribusi Karakteristik Responden Berdasarkan Umur

\begin{tabular}{|c|c|c|c|}
\hline No & Kelompok umur & Frekuensi & Prosentase \\
\hline 1 & $40-65$ tahun & 10 & 83,4 \\
2 & $>65$ tahun & 2 & 16,6 \\
\hline & Total & 12 & 100 \\
\hline
\end{tabular}

Tabel 2 Distribusi Karakteristik Responden Berdasarkan Riwayat Pekerjaan

\begin{tabular}{|c|l|c|c|}
\hline No & Pekerjaan & Frekuensi & Prosentase \\
\hline 1 & $\begin{array}{l}\text { Pernah Bekerja } \\
2\end{array}$ & 3 & 25 \\
& $\begin{array}{l}\text { Tidak pernah } \\
\text { bekerja }\end{array}$ & 9 & 75 \\
\hline \multicolumn{2}{|c|}{ Total } & 12 & 100 \\
\hline
\end{tabular}

Tabel 3 Uji Normalitas Data Menggunakan Kolmogorov Smirnov Berdasarkan Tekanan Darah Sebelum dan Sesudah Dilakukan Senam Lansia

\begin{tabular}{|l|l|l|}
\hline & sebelum & sesudah \\
\hline $\mathrm{N}$ & 12 & 12 \\
\cline { 2 - 3 } Normal parameter & 151,67 & 135,83 \\
\cline { 2 - 3 } & 10,299 & 9,962 \\
\cline { 2 - 3 } & .314 & .245 \\
\cline { 2 - 3 } & .314 & .171 \\
\cline { 2 - 3 } & -186 & -245 \\
\cline { 2 - 3 } Kolmogorov Smirnov & 1.089 & .850 \\
\cline { 2 - 3 } Asymp. Sig. (2-tailed) & .187 & .465 \\
\hline
\end{tabular}

Tabel 4 Distribusi Mean, SD, Berdasarkan Tekanan Darah Sistol Sebelum dan Sesudah Senam Lansia

\begin{tabular}{|l|l|l|l|l|}
\hline & Mean & N & $\begin{array}{l}\text { Std. } \\
\text { Deviasi }\end{array}$ & $\begin{array}{l}\text { Std. } \\
\text { Error } \\
\text { Mean }\end{array}$ \\
\hline Sebelum & 151.65 & 12 & 10.299 & 2.973 \\
\hline Sesudah & 135.83 & 12 & 9.962 & 2.876 \\
\hline
\end{tabular}

sistol sebelum senam adalah 151,65 sedangkan sesudah senam didapatkan rata-rata 135.83. berdasarkan uji Paired Sample $\mathrm{T}$ Test didapatkan derajat kemaknaan 0,05 sehingga $\mathrm{H}_{0}$ ditolak dan $\mathrm{H} 1$ diterima artinya ada hubungan senam lansia dengan penurunan tekanan darah sistol.

\section{PEMBAHASAN}

Penelitian yang dilakukan dari 12 responden, sebagian besar berusia 40-65 tahun $(83,4)$, umur tersebut masuk dalam kategori prasenium. Seluruh lansia yang dilakukan penelitian berdasarkan Tabel 4, masuk dalam kategori hipertensi kategori 1 di mana rata-rata tekanan darah sistol 151. Penatalaksanaan hipertensi kategori 1 adalah dengan menurunkan risiko penyakit kardiovaskuler dan mortalitas yaitu dengan cara modifikasi gaya hidup. (Mansjoer, 2001). Gaya hidup di sekitar tempat penelitian dalam kategori sederhana di mana sebagian besar responden memiliki riwayat tidak bekerja sehingga aktifitas yang dilakukan dirumah tidak terlalu banyak.

Bertambahnya usia dapat menyebabkan terjadinya peningkatan tekanan darah sistolik secara progresif. Untuk menghindarkan terjadinya peningkatan tersebut lansia sangat membutuhkan latihan fisik secara teratur dan rileks, salah satunya dengan senam. Peningkatan kualitas hidup secara mental yang diperoleh melalui aktivitas fisik ialah mengurangi stres, meningkatkan rasa antusias dan rasa percaya diri, serta mengurangi kecemasan dan depresi seseorang terkait dengan penyakit yang dialaminya. (Taylor, CB, 1985)

Senam lansia merupakan salah satu upaya untuk meningkatkan kesegaran jasmani kelompok lansia yang jumlahnya semakin bertambah, sehingga perlu diberdayakan dan dilaksanakan secara benar, teratur, dan rutin. Senam lansia dapat membantu kekuatan pompa 
jantung agar bertambah, sehingga aliran darah bisa kembali lancar, dikarenakan pada usia lanjut kekuatan mesin pompa jantung berkurang, dan berbagai pembuluh darah penting khusus di jantung dan otak mengalami kekakuan. (Isesreni, 2011)

Tujuan senam lansia lebih diarahkan pada pembentukan lansia yang sehat dinamis, yaitu mempunyai kemampuan gerak, mampu mendukung segala kegiatan, dan kreativitas bagi peningkatan kesejahteraan hidup lansia. Selain menjaga kesehatan pada lansia, senam pada lansia juga mampu mencapai lansia yang sehat secara fisik, mental dan social yang tetap mampu bersosialisasi dengan teman sekeliling sehingga dapat mengurangi tingkat stress. (Tegawati, dkk 2009)

Perbedaan perubahan tekanan darah sistolik sebelum dan setelah diberikan senam lansia terdapat penurunan rata-rata tekanan darah sistolik sebanyak 15,82 $\mathrm{mmHg}$ dari 151,65 mmHg menjadi $135,83 \mathrm{mmHg}$ dengan nilai $\mathrm{p}=$ 0,000. Hal ini mengindikasikan bahwa terjadi penurunan nilai rata-rata tekanan darah sistolik setelah dilakukan senam lansia.

\section{KESIMPULAN}

Terdapat hubungan yang significant antara senam lansia dengan penurunan tekanan darah sistol pada lansia.

\section{DAFTAR PUSTAKA}

Arif Mansjoer, 2001 Kapita Selekta Kedokteran, Jakarta Isesreni \& Minropa A. 2011. Pengaruh senam Lansia Terhadap Penurunan Tekanan

Nugroho Wahjudi, (2008), Keperawatan Gerontik dan Geriatri. edisi 3. Jakarta, EGC

Setiawan GW, Wungouw HIS \& Pangemanan DHC. 2013 Pengaruh Senam Bugar Lanjut Usia (Lansia) Terhadap Kualitas Hidup Penderita Hipertensi. Jurnal e-Biomedik (eBm). 1(2): 760-4.

Siti Bandiyah, 2009 Lanjut Usia dan Keperawatan Gerontik, Yogyakarta

Siti Maryam, 2008 Mengenal Usia Lanjutdan Perawatannya, Jakarta

Taylor CB, Sallis JF \& Needle R. 1985 The relation of physical activity and exercise to mental health. Journal of Public health reports; 100(2): 195-202.

Tegawati LM, Karini SM, \& Widya R. 2009 Pengaruh Senam Lansia Terhadap penurunan Tingkat Depresi Pada OrangLanjut Usia. Jurnal Psikologi. 1(2): 36-45. 